\title{
Comparison of neural networks and regression time series in predicting export from Czech Republic into People's Republic of China
}

\author{
Tomáš Krulický ${ }^{*}$, Tomáš Brabenec ${ }^{2}$ \\ ${ }^{1}$ University of Žilina, The Faculty of Operation and Economics of Transport and Communications, \\ Univerzitná 8215/1, 01026 Žilina, Slovakia \\ ${ }^{2}$ University of Economics, Faculty of Finance and Accounting, nám. W. Churchilla 1938/4, 13067 \\ Prague, Czech Republic
}

\begin{abstract}
The People's Republic of China is one of the largest, but also the most demanding markets in the world. The trade is limited by a number of barriers, strong competition and unusual environment for trades from other parts of the world. Despite those limitations, Czech exporters are able to establish themselves in the Chinese market, exporting mainly machines and vehicles. To predict future export trends is very difficult; however, these predictions can be crucial not only for individual exporters but also for the whole national economy. For predictions, economists use causal, intuitive or statistical methods. The objective of the contribution is to compare the accuracy of equalizing time series by means of regression analysis and artificial neural networks for a possible prediction of future export trends on the example of the Czech Republic export to the People's Republic of China. For the purposes of analysis by means of statistical methods, the data obtained from monthly statements from the period starting from the year 2000 and ending in July 2018. First, a linear regression is carried out and subsequently, neural networks are used for regression. Finally, the results are compared. It appeared that in practice, mainly all retained neural networks are applicable. However, the first of them showed significant deviations within a very short period of time.

Key words: export, artificial neural networks, regression analysis, time series, prediction
\end{abstract}

\section{Introduction}

Since the first computers were created, the best programmes have been striving for creating an algorithm that would be able to imitate the activity of human brain. The result of these efforts is later referred to as artificial intelligence, or artificial neural networks [1].

According to [2] artificial neural networks are inspired by biological neural network, where a fundamental building block is a neural cell, or neuron. [3] adds individual neurons

\footnotetext{
* Corresponding author: krulicky@mail.vstecb.cz
} 
are connected by weighted links. Such links and the ability to adapt the weights (to learn) on the basis of training algorithms in the data provide a wide range of possible applications. [4] states that compared to routine methods, neural networks have a number of advantages. [5] mentions e.g. their easy use, clarity, high accuracy when analyzing complex patterns, ability to work with a large amount of data, etc. On the other hand, their disadvantages consist in the method of creating individual artificial neural networks models and requirement for extensive sample data [6].

There are a number of possibilities for the application of neural networks [7]. According to [8] artificial neural networks can be used e.g. for regression or classification of time series. [9] state that time series is a form of chronological sequence of data. Simply said, time series is a sequence of values of an indicator (economic, physiological, technological, etc.). [10] adds that time series can be found e.g. in physics, medicine, economics, but also in meteorology. In various fields of human activities, there are efforts to define the development of the given indicator in the past, to identify the factors behind the variety and make predictions for the future [11]. If a company wants to prosper and be competitive in market environment, it should perform a regular financial analysis of its activities, assess its achievements and failures and use the results for predicting the future development of the company [12].

And prediction, namely the prediction of the development of the Czech export to the PRC is what this contribution deals with. [13]. sees export as a macroeconomic term describing the overall volume of products and services purchased by foreign entities expressed in financial terms. [14] state that both the Czech Republic and the People's Republic of China rank among the countries with open economy. According to [15] the Czech Republic is the PRC 18th largest market. [16] add that the CR exports to China show a long-term upward trend. The largest increase was recorded in 2007 (by almost 60\%) and in 2010 (by 53\%). There was also a large increase in 2011 (by more than 30\%). In 2012 and 2013, the growth was between $8-11 \%$. It shows that the export volumes have tripled since 2007. In the last five years they have increased roughly by 70\% [17]. In 2017, Czech export to China amounted to CZK 56 billion, which represents a year-to-year increase by $20 \%$ and historic record export from the CR to China. China is considered one of the largest, but also the most demanding world markets. Business is characterized by countless barriers, strong competition and unusual environment for Europe. Despite of this, Czech exporters are steadily successful in establishing themselves in Chinese market. In 2014 Czech export to China amounted to CZK 42.5 billion [15]. According to [18] Czech export to China consists especially of machines and vehicles, accounting for more than a half of direct export. Furthermore, the Czech Republic also exports industrial and consumer goods, mainly motor vehicle components, pumps, switchboards, telephones, circuits, toys, prams, and tires.

The objective of the contribution is to compare the accuracy of balanced time series by means of regression analysis and neural networks using the example of the Czech Republic (CR) export to the People's Republic of China.

\section{Data and methods}

Data used for analysis are available on websites of the World Bank, etc. For the purposes of the analysis, the information / data on the Czech Republic export to the People's Republic of China. The period for which the data are available is monthly statement for the period from January 2000 to July 2018, that is, 223 input data. Currency is Euro.

Descriptive characteristics of the data are given in Table 1. 
Table 1. Data set characteristics

\begin{tabular}{|l|r|r|}
\hline \multicolumn{1}{|c|}{ Samples } & Month (Input variable) & Export (output - target ) \\
\hline Minimum (Training) & 36526.00 & 2454273 \\
\hline Maximum (Training) & 43252.00 & 201110297 \\
\hline Mean (Training) & 39916.52 & 72336830 \\
\hline Standard deviation (Training) & 1949.82 & 57137498 \\
\hline Minimum (Testing) & 36586.00 & 2941297 \\
\hline Maximum (Testing) & 43282.00 & 189894269 \\
\hline Mean (Testing) & 39702.30 & 68339319 \\
\hline Standard deviation (Testing) & 2174.13 & 61536318 \\
\hline Minimum (Validation) & 36951.00 & 6079350 \\
\hline Maximum (Validation) & 43040.00 & 204067342 \\
\hline Mean (Validation) & 40047.88 & 78077699 \\
\hline Standard deviation (Validation) & 3096.16 & 71615096 \\
\hline Minimum (Overall) & 36526.00 & 2454273 \\
\hline Maximum (Overall) & 43282.00 & 204067342 \\
\hline Mean (Overall) & 39904.26 & 72594815 \\
\hline Standard deviation (Overall) & 1963.77 & 57933645 \\
\hline
\end{tabular}

Source: Own processing.

An interesting phenomenon is the development of the export over time. Figure 1 shows graphs representing statistical characteristics including an input data histogram.

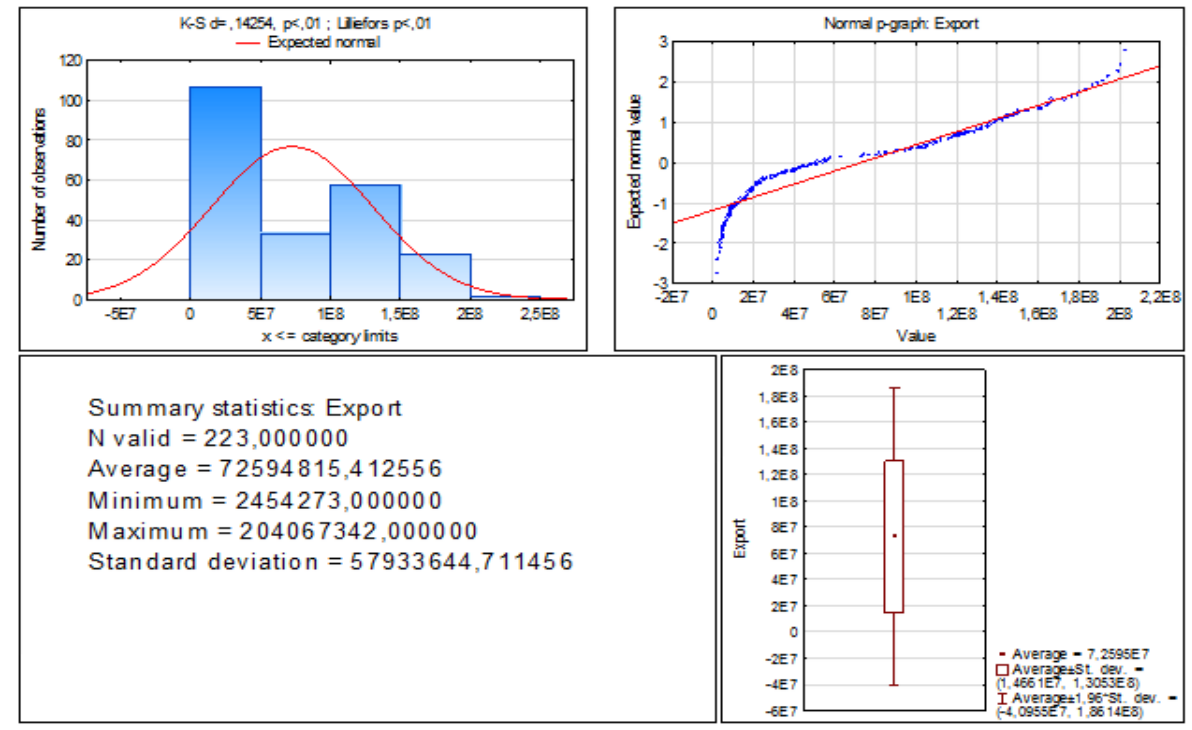

Fig. 1. Graph of basic statistical characteristics

Source: Own processing

The histogram shows that the major changes were in the lowest quintile. For data processing, DELL's Statistica software, version 12 will be used. Firstly, linear regression will be carried out. Subsequently, neural networks will be used for regression.

Linear regression will be performed on the examined sample for the following functions: 
- Linear,

- Polynomial,

- Logarithmic,

- Exponential,

- Distance weighting polynomial,

- Negative-exponential smoothing polynomial.

Firstly, correlation coefficient, that is, the dependence of CR export to PRC on time will be calculated. We will work with the significance level 0.95 .

Subsequently, regression using neural networks will be carried out. Multilayer perceptron network and radial basis function network will be generated. Time will be an independent variable. A depended variable will be CR export to PRC. The time series will be divided into three sets - training, testing and validation. The first set will contain $70 \%$ of input data. Based on the training data set, neural structures will be generated. The two remaining data sets will contain $15 \%$ of input data each. Both data sets will be used for verification of the generated neural structure, or model reliability. The delay of the time series will be 1. 10,000 neural networks will be generated, out of which five with the best characteristics* will be retained. The hidden layer will contain no less than two and no more than 50 neurons. For the radial basis function network, the number of neurons in the hidden layers will be no less than 21 and no more than 30 . For the multilayer perceptron network, the following distribution function in the hidden and output layer will be considered:

- Linear,

- Logistic,

- Atanh,

- Exponential,

- Sinus.

Other settings will be default (according to the ANS tool - automated neural networks).

Finally, the results of linear regression and regression by means of neural networks will be compared. The comparison will not be through residual analysis (minimum and maximum values, the dispersion of residuals, etc.) but as expert view and through the experience of the evaluator (economist).

\section{Results}

\subsection{Linear regression}

The correlation coefficient is 0.9605 , which indicates a statistically significant direct dependence of export on the development over time. The coefficient of determination achieves the value of 0.9226 .

A scatter plot (see Figure 2) was drawn up, where the individual points were fitted with a regression curve, linear in this case. The curve parameters are shown in the figure.

\footnotetext{
* The method of least squares will be used. Generating of networks will be finished when there is no improvement, i.e. when the sum of the squares is not lower. We will retain the neural structures whose sum of the residual square compared to the actual development of CR export to PRC is as low as possible (zero in ideal case).
} 


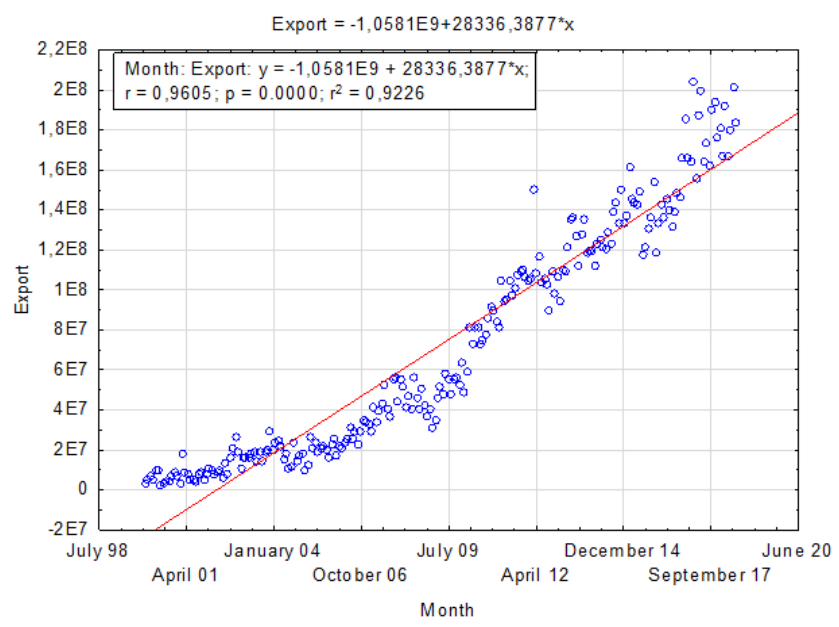

Fig. 2. Scatter plot representing the CR export to PRC, fitted with regression curve - linear function Source: Own processing.

The red line represents the regression function. Linear function quite corresponds with the development of CR export to PRC.

Figure 3 represents fitting the scatter plot with a polynomial function.

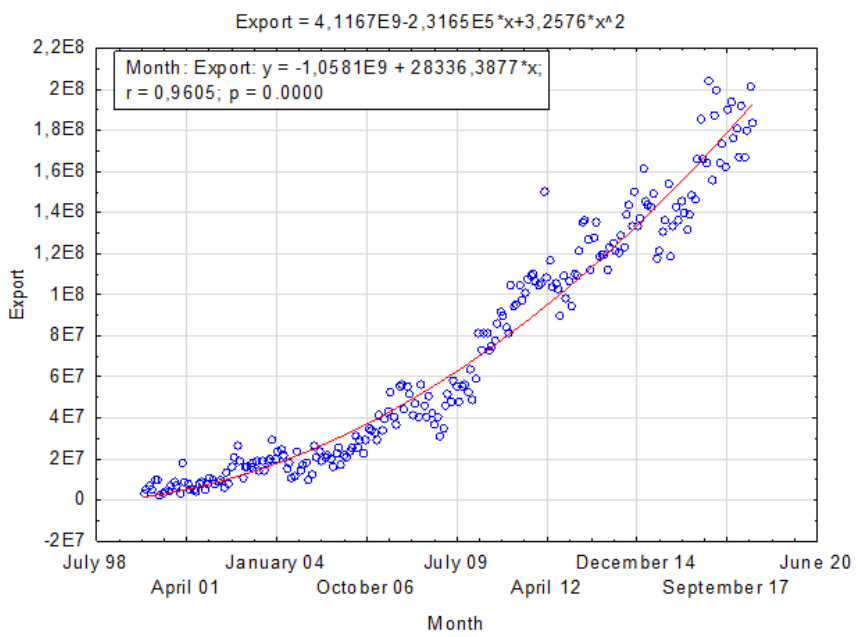

Fig. 3. Scatter plot of CR export to PRC fitted with a regression curve -polynomial function Source: Own processing.

In this case, the solid red line also represents the regression curve. Its shape corresponds with the development trend of the CR export to PRC, optically even better than the curve in the Figure 2.

Figure 4 shows a scatter plot fitted with a logarithmic function. 


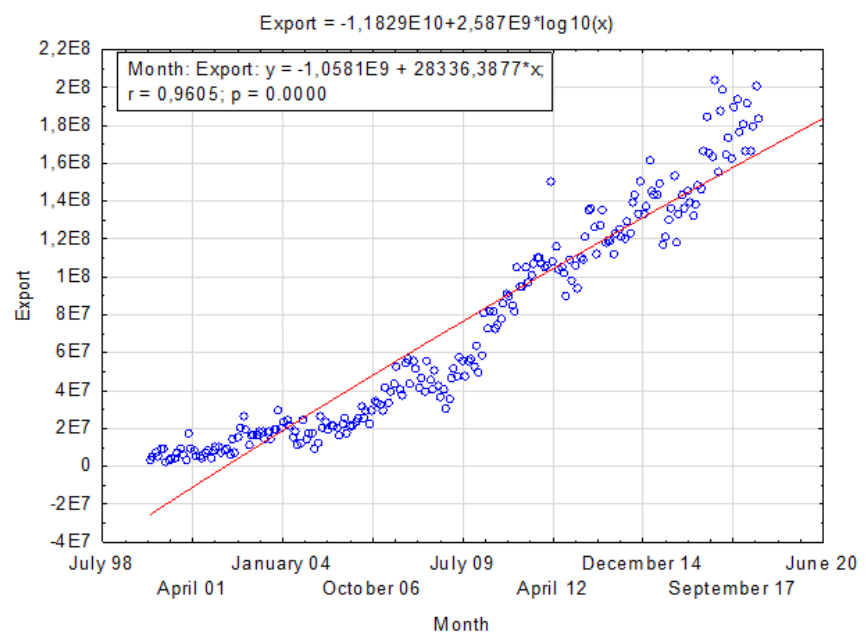

Fig. 4. Scatter plot of CR export to PRC fitted with a regression curve - logarithmic function

Source: Own processing.

The logarithmic function curve is similar to the linear function. However, its position in the graph is a bit different. It results from the position of the individual points in the graph that logarithmic function is not convenient for regression.

Figure 5 shows a scatter plot of the CR export to PRC fitted with a LOWESS function.

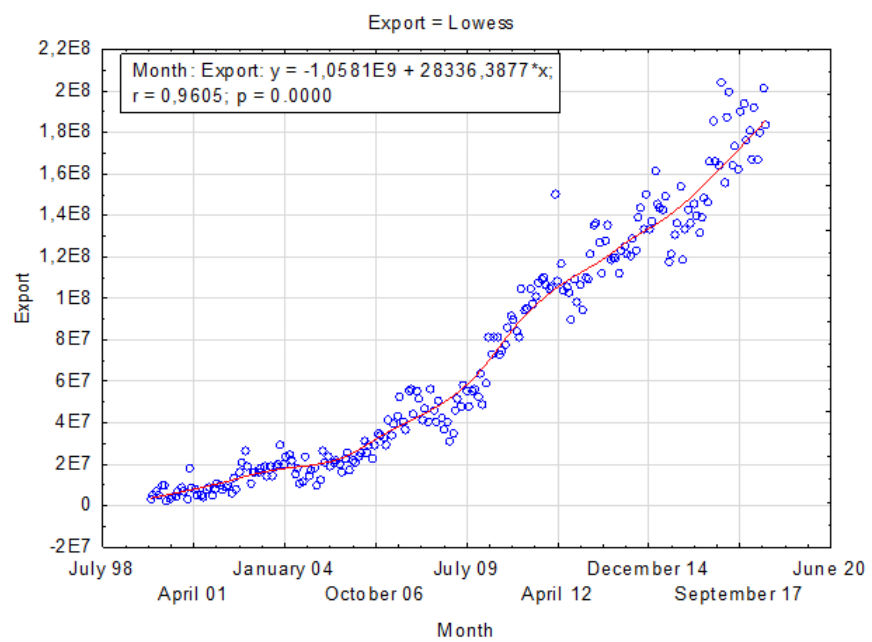

Fig. 5. Scatter plot of CR export to PRC fitted with regression curve - LOWESS

Source: Own processing.

LOWESS (locally weighted scatterplot smoothing) function, or also LOES (locally estimated scatterplot smoothing) function is calculated as a regression function in partial intervals. The LOWESS function curve balances the time series and follows its trend. The graph fitted with the LOWESS curve is very interesting. It enables to reveal the development trend of the monitored variable.

Figure 6 shows a scatter plot of the CR export to PRC development fitted with the function obtained by means of the method of the least squares of weighted distance. 


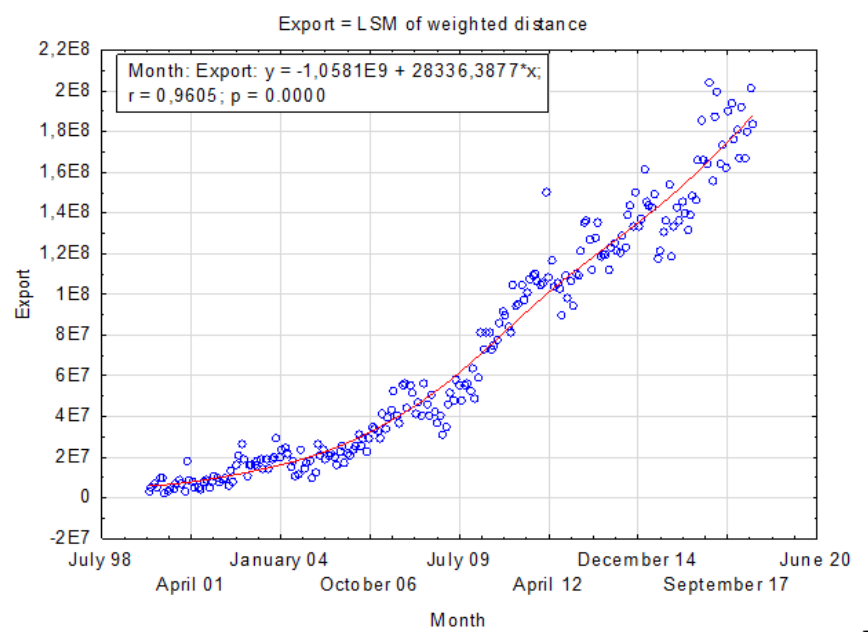

Fig. 6. Scatter plot of CR export to PRC fitted with regression curve - function LSM of weighted distance

Source: Own processing.

The curve follows the development of export in the entire interval much better than the linear, polynomial and logarithmic function.

Figure 7 shows fitting the graph with the function obtained by means of the least squares method negatively - by exponential smoothing.

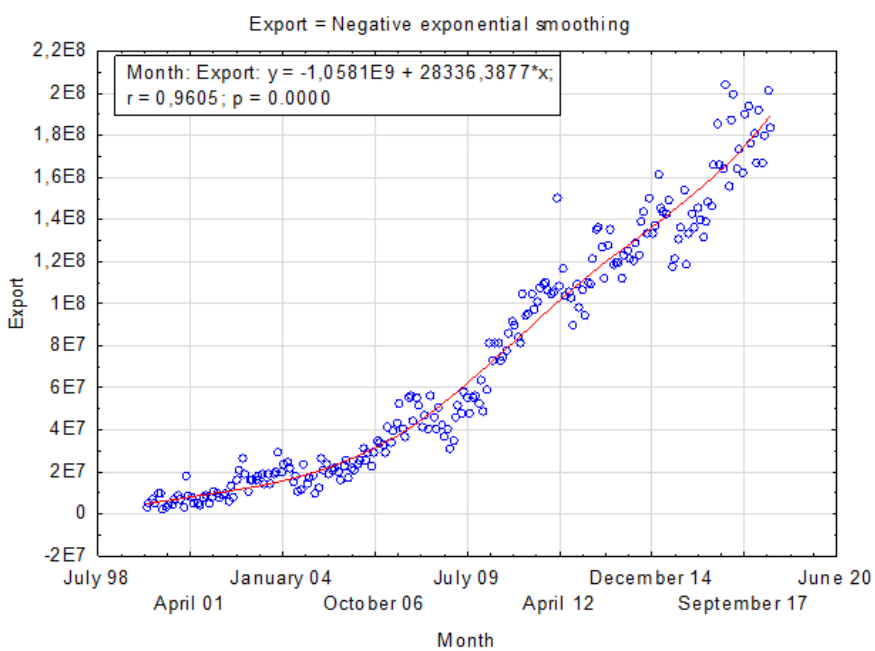

Fig. 7. Scatter plot of CR export to PRC fitted with regression curve - the LSM function - negatively exponential smoothing

Source: Own processing.

Even this curve appears to be interesting and convenient for a possible forecast. It also has better results than the linear, polynomial and logarithmic function.

The correlation coefficient indicates a significant statistical direct dependence of the target variable on the development over time [19]. Its value achieves 0.9605 . The coefficient of determination is 0.9226 . If assessing the results only by visual comparison of 
the $\mathrm{CR}$ export to PRC and the regression line shape, considering also the simple linear regression, it could be stated that the development trend is best illustrated by the LOWESS function. Other convenient ones are the curve obtained by means of the method of least squares, more specifically by negative-exponential smoothing and weighted distance. All the three functions follow the trend of the CR export to PRC development trend. It should be also stated that the other functions (linear, polynomial and logarithmic functions) are not convenient for balancing the time series, as they simplify its course.

\subsection{Neural structures}

Based on the established procedure, 10,000 neural networks were generated, out of which 5 with the best characteristics were retained. The generated structures are given in Table 2 .

Table 2. Retained neural networks

\begin{tabular}{|c|c|c|c|c|c|c|c|c|c|c|}
\hline Network & $\begin{array}{c}\text { Train. } \\
\text { perform. }\end{array}$ & $\begin{array}{c}\text { Test. } \\
\text { perform. }\end{array}$ & $\begin{array}{c}\text { Valid. } \\
\text { perform. }\end{array}$ & Train. error & Test. error & $\begin{array}{l}\text { Validation } \\
\text { error }\end{array}$ & $\begin{array}{c}\text { Train. } \\
\text { algorithm }\end{array}$ & $\begin{array}{c}\text { Error } \\
\text { function }\end{array}$ & $\begin{array}{c}\text { Activation } \\
\text { of hidden } \\
\text { layer }\end{array}$ & \begin{tabular}{|c|} 
Output \\
activation \\
function \\
\end{tabular} \\
\hline $\begin{array}{l}\text { RBF } \\
1-25-1\end{array}$ & 0.985012 & 0.980579 & 0.987450 & $4.771255 \mathrm{E}+13$ & $7.444074 \mathrm{E}+13$ & $5.083755 \mathrm{E}+13$ & RBFT & Sum.quart. & Gauss & Identity \\
\hline $\begin{array}{l}\text { RBF } \\
1-24-1\end{array}$ & 0.986758 & 0.988762 & 0.988485 & $4.217975 \mathrm{E}+13$ & $4.178269 \mathrm{E}+13$ & $4.393104 \mathrm{E}+13$ & RBFT & Sum.quart. & Gauss & Identity \\
\hline $\begin{array}{l}\text { RBF } \\
1-22-1\end{array}$ & 0.984784 & 0.984158 & 0.987483 & $4.843365 \mathrm{E}+13$ & $5.948545 \mathrm{E}+13$ & $4.857253 \mathrm{E}+13$ & RBFT & Sum.quart. & Gauss & Identity \\
\hline $\begin{array}{l}\text { RBF } \\
1-29-1\end{array}$ & 0.987128 & 0.985992 & 0.987617 & $4.100611 \mathrm{E}+13$ & $5.522412 \mathrm{E}+13$ & $4.713247 \mathrm{E}+13$ & RBFT & Sum.quart. & Gauss & Identity \\
\hline $\begin{array}{l}\text { RBF } \\
1-28-1\end{array}$ & 0.988870 & 0.986798 & 0.987984 & $3.547655 \mathrm{E}+13$ & $4.972306 \mathrm{E}+13$ & $4.766382 \mathrm{E}+13$ & RBFT & Sum.quart. & Gauss & Identity \\
\hline
\end{tabular}

Source: Own processing.

The networks are only the radial basis function networks. There is only one variable (time) in the input layer. The neural networks in the hidden layer contain 22-28 neurons. Logically, the output layer contains only one neuron and one output variable - CR export to PRC. In all networks, training algorithm RBFT was applied. In addition, for activating the hidden layer all neural networks used the same function, Gauss curve. Similarly, for activating the output layer the same function (identity function) is used (for more details, see Table 2).

Another interesting fact is a training, testing and validation performance. In general, we are looking for a network with ideally the same performance in all data sets (as stated before, the division of data into data sets was random). The error should be as small as possible. As for the error, it should be noted that export in EUR, that is, a detailed export is concerned. This will be reflected in the calculation of error.

The performance of the individual data sets is expressed in the form of the correlation coefficient. The values of the individual data sets by specific neural networks are given in Table 3.

Table 3. Individual data sets correlation coefficients

\begin{tabular}{|l|r|r|r|}
\hline & Exports (Training) & Exports (Testing) & Exports (Validation) \\
\hline 1.RBF 1-25-1 & 0.985012 & 0.980579 & 0.987450 \\
\hline 2.RBF 1-24-1 & 0.986758 & 0.988762 & 0.988485 \\
\hline 3.RBF 1-22-1 & 0.984784 & 0.984158 & 0.987483 \\
\hline 4.RBF 1-29-1 & 0.987128 & 0.985992 & 0.987617 \\
\hline 5.RBF 1-28-1 & 0.988870 & 0.986798 & 0.987984 \\
\hline
\end{tabular}

Source: Own processing. 
It results from the table that the performance of all retained neural structures is very high. The correlation coefficient value of all training data sets is in the interval of 0.984 to almost 0.989 . The correlation coefficient of the validation data sets for all neural networks is above 0.987 . To choose the most suitable neural structure, a detailed analysis of the results obtained must be carried out. Table 4 shows the basic statistical characteristics of the individual data sets for all neural structures.

Table 4. Statistics of individual data sets by retained neural structures

\begin{tabular}{|c|c|c|c|c|c|}
\hline Statistics & $\begin{array}{l}1 . \mathrm{RBF} \\
1-25-1\end{array}$ & $\begin{array}{l}2 . \mathrm{RBF} \\
1-24-1\end{array}$ & $\begin{array}{l}3 . \mathrm{RBF} \\
1-22-1\end{array}$ & $\begin{array}{l}4 . \mathrm{RBF} \\
1-29-1\end{array}$ & $\begin{array}{l}5 . \mathrm{RBF} \\
1-28-1\end{array}$ \\
\hline Minimum forecast (Training) & -8418893 & 3472318 & 9180892 & 1251742 & 4918553 \\
\hline Maximum forecast (Training) & 190822276 & 186070372 & 181203377 & 187395786 & 180517887 \\
\hline Minimum forecast (Testing) & -7161402 & 4078977 & 9180892 & 68287 & 5140141 \\
\hline Maximum forecast (Testing) & 188177859 & 185241939 & 176690372 & 188231841 & 179655155 \\
\hline Minimum forecast (Validation) & 3894649 & 3794002 & 9180893 & 5962466 & 6206731 \\
\hline Maximum forecast (Validation) & 190126526 & 185920027 & 180856649 & 188088008 & 180308749 \\
\hline Minimum residuals (Training) & -34967735 & -27425467 & -27924255 & -26036132 & -22551514 \\
\hline Maximum residuals (Training) & 33790350 & 41984963 & 53868193 & 35793399 & 44478206 \\
\hline Minimum residuals (Testing) & -26450342 & -22970109 & -14708615 & -25960011 & -26960987 \\
\hline Maximum residuals (Testing) & 19614324 & 29080375 & 40809726 & 23105018 & 31063549 \\
\hline Minimum residuals (Validation) & -16056606 & -13641111 & -14345343 & -14204405 & -13700966 \\
\hline Maximum residuals (Validation) & 25744050 & 22330673 & 23210693 & 24535173 & 26859519 \\
\hline Minimum standard residua (Training) & -5 & -4 & -4 & -4 & -4 \\
\hline Maximum standard residuals (Training) & 5 & 6 & 8 & 6 & 7 \\
\hline Minimum standard residuals (Testing) & -3 & -4 & -2 & -3 & -4 \\
\hline Maximum standard residuals (Testing) & 2 & 4 & 5 & 3 & 4 \\
\hline Minimum standard residuals (Valid.) & -2 & -2 & -2 & -2 & -2 \\
\hline Maximum standard residuals (Valid.) & 4 & 3 & 3 & 4 & 4 \\
\hline
\end{tabular}

Source: Own processing.

Ideally, the individual statistics of neural network are identical across all the data sets (minimum, maximum, residuals etc.). In the case of balanced time series differences can be seen both between the individual data sets of one neural network and between the individual neural networks. Bigger differences can be seen in the residuals characteristics. However, it is not possible to clearly identify which of the retained neural networks has the most suitable results.

Figure 8 represents a line graph predicting the actual development of the CR export to PRC and the development of forecasts using the individual generated and retained neural networks.

It follows from the graph that all neural networks predict different development of export in the individual intervals. The important thing, however, is not the similarity of the individual networks forecasts but the similarity (or the degree of commonality) with the actual export development. 


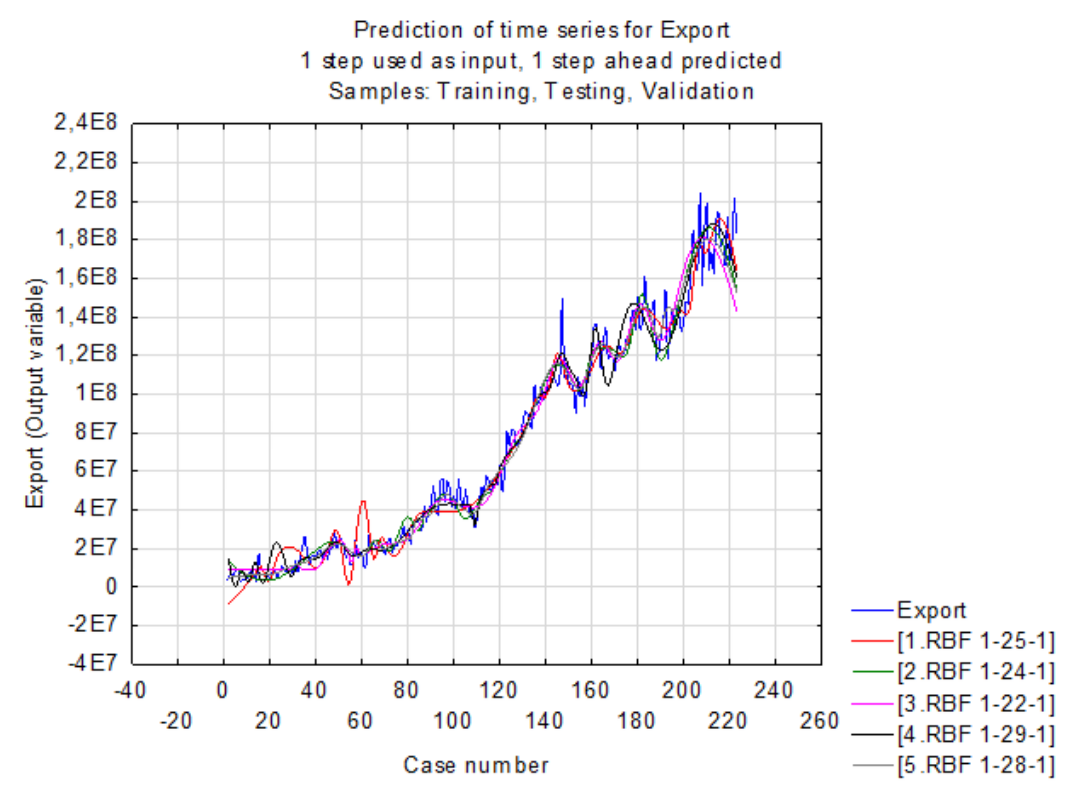

Fig. 8. Line graph - development of CR export to PRC predicted using neural network compared to the actual development in the monitored period

Source: Own processing.

Examining the course of the individual curves and their conformity with the actual CR export to PRC development it can be concluded that all neural networks follow the development of the variable relatively well. Only the $1^{\text {st }}$ RBF $1-25-1$ network in the interval between the $4^{\text {th }}$ and $80^{\text {th }}$ monitored case show significant differences from the actual development.

\section{Conclusion}

The objective of the contribution was to compare the accuracy of balancing the time series using regression analysis and neural networks on the example of Czech Republic export to People's Republic of China.

In general, each forecast is determined by a certain fulfilment probability degree. When predicting the future development of any variable, the forecast of its development based on the data from the previous periods is sought to be made. Although most factors influencing the target variable can be considered, certain simplification of reality always occurs and thus there is always a certain degree of probability that the forecast will come true [20]. Both in the case of linear regression and regression by means of neural networks, quite a significant simplification occurs. We work with two variables only - input (time) and output (CR export to PRC) variable. Other input variables, often significantly influencing the level of CR export to PRC (international political situation, taxation in both countries, cost of production factors, government export subsidies, size of both countries, raw material wealth of both countries, standards of living, consumption behaviour of the inhabitants, etc.) are thus not considered. The crucial factor is the purpose of the calculation. Such simplification will be sufficient for predicting the future development of the individual states economy development based on the monitored variable and the calculation will have adequate information value. However, when planning the transportation capacity of a 
specific company, the simplification in the form of balancing time series will not be sufficient, as it holds true that the aggregated variables can be predicted more easily than the partial variables.

It can also be stated that due to the simplification it is not possible to predict emergency situations and their impact on the CR export to PRC (at least not in the long-term run). It would thus be ideal to make a short-term (days) forecast; however, it is not possible to obtain data for the purpose of a short-term forecast.

The CR export to PRC can be predicted based on the statistical, causal and intuitive methods. In this contribution, the focus was on comparing the statistical methods. However, this only helped us to create a framework of the monitored variable development. What is important is to process the information about the possible future development of economic, politic or legal environment. If we are able to predict the development, it could be considered when monitoring the selected variable. At the same time, however, the evaluator should be considered, an economist who is able to correlate with the resulting variable determined based on the framework of the statistical methods and specified based on the causal links on the basis of their knowledge and experience.

Optically, the LOWESS curve appeared to be the most convenient in terms of the linear regression. The other convenient ones were the curve obtained by means of the method of least squares by negative exponential smoothing and by means of the methods of least squares of weighted distance. All neural networks turned out to be applicable. Only the 1 st RBF 1-25-1 neural network showed more significant deviations in a very short time interval.

The objective of the contribution was achieved.

\section{References}

1. D. Chicea, S.M. Rei, A fast artificial neural network approach for dynamic light scattering time series processing. Measurement Science and Technology, 29(10) (2018)

2. M.S. Hossain, Z.C. Ong, Z. Ismail, S. Noroozi, S.Y. Khoo, Artificial neural networks for vibration based inverse parametric identifications: A review. Applied Soft Computing, 52, 203-219 (2017)

3. M.V. Cho. Learning Process in a Neural Network Model. Journal of the Korean Physical Society, 74(1), 63-72 (2019)

4. M. Vochozka, Formation of complex company evaluation method through neural networks based on the example of construction companies' collection. AD ALTAJournal of Interdisciplinary Research, 7(2), 232-23 (2017)

5. Q.J. Zhu, L.C. Tian, X.H. Yang, L.F. Gan, N. Zhao, Y.Y. Ma, Advantages of Artificial Neural Network in Neutron Spectra Unfolding. Chinese Physics Letters, 31(7) (2014)

6. Z. Rowland, J. Vrbka, Using artificial neural networks for prediction of key indicators of a company in global world. 16th International Scientific Conference on Globalization and its Socio-Economic Consequences, pp. 1896-1903. ISBN 978-808154-191-9 (2016)

7. D. Sánchez, P. Melin, Modular Neural Networks for Time Series Prediction Using Type-1 Fuzzy Logic Integration. Studies in Computational Intelligence: Design of intelligent systems based on fuzzy logic, neural networks and nature-inspired optimization, 601, 141-145 (2015)

8. M. Deng, W.T. Yang, G.L. Liu, R. Jin, F. Xu, Y. Zhang, Heterogeneous SpaceTime Artificial Neural Networks for Space-Time Series Prediction. Transactions in GIS, 22(1), 183-201 (2018) 
9. M.K. Rafsanjani, M. Samareh, Chaotic time series prediction by artificial neural network. Journal of Computational Methods in Sciences and Engineering, 16(3), 599-615 (2016)

10. B. Wang, S.H. Xu, X.H. Yu, P.C. Li, Time Series Forecasting Based on Cloud Process Neural Network. International Journal of Computational Intelligence Systems, 8(5) 992-1003 (2015)

11. F. Fernandez-Navarro, M.A. de la Cruz, P.A. Gutierrez, A. Castano, C. HervasMartinez, Time series forecasting by recurrent product unit neural network. Neural Computing \& Applications, 29(3), 779-791 (2017)

12. T. Klieštik, J. Vrbka, Z. Rowland, Bankruptcy prediction in Visegrad group countries using multiple discriminant analysis. Equilibrium - Quarterly Journal of Economics and Economic Policy, 13(3), 569-593 (2018)

13. Ministry of Industry and Trade - MIT, Export v ekonomice [Export in economy] [online], Available at: https://www.mpo.cz/ (2018)

14. J. Gourdon, S. Monjon, S. Poncet, Trade policy and industrial policy in China: What motivates public authorities to apply restrictions on exports? China Economic Review, 40, 105-120 (2016)

15. Business info.cz., China: Trade and Economic Cooperation with the Czech Republic, [online], Available at: https://www.businessinfo.cz/cs/clanky/cina-obchodni-aekonomicka-spoluprace-s-cr-19054.html (2018)

16. V. Stehel, P. Šuleř, Foreign trade between China and the Czech Republic. Littera Scripta, 9(3), 84-95 (2016)

17. V. Humlerová, Czech-Chinese Business Cooperation Case Study. 31st InternationalBusiness-Information-Management-Association Conference Innovation management and education excellence through vision 2020, pp. 3185-3191 (2018)

18. P. Higgins, T. Tha, W. Zhong, Forecasting China's economic growth and inflation. China Economic Review, 41, 46-61 (2016)

19. T. Klieštik, M. Mišánková, K. Valášková, L. Švábová, Bankruptcy prevention: new effort to reflect on legal and social changes. Science and Engineering Ethics, 24(2), 791-803 (2018)

20. Ch. Bolton, V. Machová, M. Kováčová, K. Valášková, The power of human-machine collaboration: Artificial intelligence, business automation, and the smart economy. Economics, Management, and Financial Markets, 13(4), 51-56 (2018) 